\title{
Transhumanism and human enhancement: A post-mortem
}

\author{
Andrés Vaccaria, b \\ a Centro de Estudios en Ciencia, Tecnología, Cultura y Desarrollo (CITECDE) Universidad Nacional de Río Negro, Argentina \\ b Philosophy Department, Macquarie University, Sydney, Australia
}

Transhumanism is an ideological movement that advocates the enhancement of human intellectual and physical capacities through technological modification. Since it burst in the scene in the 1990s, its popularity has grown in inverse proportion to its relevance. However, I believe that transhumanism has already failed to convince us that we must radically transform the human condition, and its failure can offer some valuable reflections on the topic of human enhancement (HE). Transhumanists talk about transcendence, overcoming nature, and fulfilling human potentials. We will take the reins of our own evolution to the point we will become "better than human". Some believe that posthumanity itself is the goal of the transhumanist project, while others claim that it will be the natural outcome of pursuing values that we already hold dear. In both cases, posthumanity is conceived as a beneficial state we should actively strive to make a reality. The politics of transhumanism is largely libertarian and exalts the sacred autonomy of the self. But libertarianism has some trouble legitimating modifications done to future others: the type of inherited, irreversible changes that will drive directed evolution (such as those resulting from germline engineering). This is why it is necessary to argue for a future, collective benefit, and posthumanity comes in to fill the gap.

The first, most obvious objection to this view is that the notion of augmenting or enhancing capacities seems to rely on the same fixed, normative notion of 'human nature' that transhumanists so desperately want to dispense with. As a way of a response, the transhumanist resorts to a Promethean view of the human as lacking any natural determination. If human existence precedes its essence, then we can remake ourselves in view of values we freely choose. Yet, in this gambit, human no-nature simply comes to play the same ontological and normative role as nature (see: [4]). As a result, the argument quickly plunges into a fallacy analogous to the naturalistic one, in the sense that normative conclusions are derived from descriptive premises about our existential constitution: having no essence is thought of as if it were a sort of essence.

Transhumanism needs a theory of values that convinces us that values are sufficiently universal to make posthumanity the conceivable and beneficial outcome of our present choices. Nick Bostrom argues that transhumanist values (higher intelligence, longevity, physi- cal and psychological capacities, etc.) are "intrinsic" ([1], p. 501; [2]). The problem is that an intrinsic good has value in itself, and it is worth pursuing even if it has dreadful consequences. Do we value intelligence for its own sake or because of the benefits it brings? Enhancements are instrumental goods, which means that enhanced capacities and beneficence (or virtue) are not causally aligned. A good life is the result of individual choices, circumstances and contexts, rather than of any specific set of capacities.

At this point, the transhumanist could argue for a conventional view: what matters is that values are shared, and it is enough that we all agree on them. The problem is that HE options will be assessed and adopted in diverse contexts and value frameworks. It is likely that individuals and cultures will not converge on a common use of genetic engineering technologies because there are no common conceptions of the good that hold across them. Transhumanists need to convince us that posthumanity represents a foreseeable and conceivable benefit. However, there is no way to calculate the aggregate result of these choices. The values that transhumanists defend are suspiciously culturally specific, yet their model of valuation has claims to universality: values are the result of rational consideration by an individual or collective in an ideal context of free and informed deliberation. As Imelda de Melo-Martín [3] writes, arguments on both transhuman and bioconservative sides "commit the error of assuming that our biological traits and behaviors can be evaluated outside of the environmental, social and political contexts in which such traits and behaviours are expressed" (p. 201). Values are also highly context-sensitive; changes in context lead to changes in values, and this frustrates even short-range attempts at evaluating the costs and benefits of any proposed technology. We cannot calculate benefits on the basis of existing values because enhancements create new frameworks that change these values, to the extent of imposing values that a person might not have otherwise endorsed.

Posthumanity cannot be an intelligible reason, let alone a good one, to take a proactive approach. We can also question some foundational assumptions. Transhumanists are fixated on new technologies; Bostrom even argues that access to new HE technologies is a moral urgency (see: [1], p. 499; [2], p. 11). This commitment to novelty is a central but questionable value choice. 
Take away the focus on shiny hi-tech and transhumanism begins to look a lot like ordinary 'humanism' - and this is precisely its point. Although, in principle, traditional means of suffering alleviation are not ruled out, you never hear transhumanists arguing for these. Advocating Third World debt relief, equitable distribution of resources, or universal health care does not make you a transhumanist - even though these means of 'enhancement' may achieve beneficial results much more widely, quickly, and effectively. Thus the transhumanist project commits us to the prioritization, not just of new technologies, but of certain human groups over others. It asks us to put the interests of future beneficiaries of these technologies above those of populations presently suffering the afflictions of war, famine, oppression and poverty.

The exclusive focus of transhumanism has been on the naturalization of the idea of HE in abstracto. However, once we recognize that there is nothing immoral or problematic with the idea of HE itself, transhumanism offers no concrete guidelines, standards or models for addressing the pressing, real questions of implementation. Obviously not all enhancements will be beneficial to all people in all circumstances. How to enhance, who, and in which conditions? What would be a 'transhumanist' approach to the complex issues regarding liability, legal frameworks, insurance policies, and health funding models? Is there a specifically transhumanist approach to, say, the role of the health professional as advisor? Transhumanists leave us in the dark. Presently, legal experts, biotechnologists, policy makers, and health care professionals are turning their attention to much more restricted and urgent questions surrounding HE. As debates on HE enter this mature stage, transhumanism has become a quaint cultural artifact that one day we may regard with quaint nostalgia - the same way we now regard Marinetti’s Futurism or Gernsback-era pulp science fiction.

\section{Correspondence}

Andrés Vaccari, PhD

Fundación Bariloche

Av. Bustillo 9500

R8402AGP-San Carlos de Bariloche

Prov. de Río Negro

Argentina

E-mail: andres.vaccari[at]mq.edu.au

\section{References}

1. Bostrom N. Human Genetic Enhancements: A Transhumanist Perspective. The Journal of Value Inquiry. 2003; 37(4): 493-506.

2. Bostrom N. Transhumanist Values. In: Adams F (ed.). Ethical Issues for the 21st Century. Charlottesville: Philosophical Documentation Center Press; 2003, pp. 3-14.

3. De Melo-Martín I. Designing People: A Post-human Future? In: Vermaas P E, Kroes P, Light A, Moore SA (eds.). Philosophy and Design; From Engineering to Architecture. Heidelberg: Springer, 2008, pp. 197-208.

4. Hauskeller M. Prometheus Unbound: Transhumanist Arguments from Human Nature. Ethical Perspectives. 2009; 16(1):3-20. 